УДК 616.366-003.7-008.5-089.168

DOI: $10.24061 / 1727-0847.18 .2 .2019 .21$

\title{
В.Б. Борисенко
}

Харківська медична академія післядипломної освіти

\section{НЕПУХЛИННЕ ПОРУШЕННЯ ПРОХІДНОСТІ ХОЛЕДОХА: ПРИЧИНИ, ДІАГНОСТИКА ТА ПРИНЦИПИ ЛІКУВАННЯ}

\begin{abstract}
Резюме. Метою дослідження є оптимізація програми комплексної діагностики та лікування хворих 3 порушенням дистальної прохідності холедоха непухлинного генезу. Матеріал та методи. Проаналізовано результати обстеження та лікування 120 хворих із дистальною непрохідністю холедоха непухлинного генезу. Діагностична програма містила клініко-лабораторну, ультразвукову діагностику, папілоскопію, ендоскопічну ретроградну холангіопанкреатографію і комп'ютерну томографію. Хірургічне лікування проводили з пріоритетним використанням транспапілярних ендобіліарних втручань, при неефективності яких виконували етапну через шкірну черезпечінкову холангіостомію під контролем УЗД i «відкриті» оперативні втручання. Результати. 3 використанням УзД ознаки жовчної гіпертензії встановлені у всіх 120 (100 \%) хворих. У 94 (78,5 \%) пацієнтів порушення дистальної прохідності холедоха супроводжувалося механічною жовтяницею. Розроблений нами діагностичний алгоритм дав змогу в 98 \% випадках встановити причину холестазу і кінцевий деталізований діагноз. Одноетапні транспапілярні втручання були ефективними в $92(76,7 \%)$ випадках. Черезшкірна черезпечінкова етапна холангіостомія виконана 5 (4,2 \%) хворим. У якості другого етапу лікування, «відкрита» холедохолітотомія і біліодігестивні анастомози зроблені 12 (10\%) хворим. 16 (13,3\%) пацієнтам, яким встановлена дисфункція сфінктера Одді, оперативне лікування не виконували. Висновки. Запропонована нами діагностична програма з використанням ультразвукової діагностики, папілоскопіі, ендоскопічної ретроградної холангіопанкреатографії дає можливість встановити деталізований діагноз у 98\% випадків. Пріоритетним способом хірургічної корекції органічної патології термінального відділу холедоха і зони великого дуоденального сосочка $є$ малоінвазивні транспапілярні втручання і тільки у випадках їх неефективності можливе проведення етапних черезпечінкових ендобіліарних декомпресаційних маніпуляцій і традиційних «відритих» оперативних втручань.
\end{abstract}

Ключові слова: дистальна непрохідність холедоха, механічна жовтяниця, ультразвукове дослідження, ендобіліарні втручання.

Синдром порушення прохідності загальної жовчної протоки донині залишається актуальною та складною хірургічною проблемою. Актуальність перш за все зумовлена значною розповсюдженістю жовчнокам'яної хвороби, збільшенням кількості операцій на органах гепатопанкреатодуоденальної зони, а також складністю топографоанатомічних співвідношень цієї зони $[1,2]$.

Серед найбільш частих причин синдрому дистальної непрохідності холедоха доброякісного генезу слід виділити холедохолітіаз, стеноз і дисфункцію великого сосочка дванадцятипалої кишки (ВСДК), гострий папіліт, стриктури і тубулярний стеноз холедоха $[4,5]$.

Об'єднаним патогенетичним фактором цих нозологічних форм $\epsilon$ різного ступеня порушення прохідності загальної жовчної протоки від дисфункіції до розвитку стійкого холестазу і синдрому механічної жовтяниці (МЖ) [6-9]. У цих пацієнтів до $60 \%$ випадків відзначається розвиток гострого холангіту і близько $20 \%$ біліарного сепсису, які протікають з ознаками поліорганної дисфункції і недостатності, а також характеризуються високою (41-53\%) летальністю [1, 2].

Незважаючи на наявний прогрес сучасної гепатобіліарної хірургії, результати лікування пацієнтів цієї групи не можна вважати задовільними. Так, до сьогодні зберігається низка невирішених питань щодо стандартизації діагностичної та лікувальної тактики захворювань, що викликають холестаз [1, 3-5]. Не визначені критерії черговості, етапності та обсягу хірургічних втручань та не розроблені підходи щодо диференціальної діагностики функціональних та органічних уражень ВСДК $[5,10,11]$.

Розробка комплексної лікувально-діагностичної програми, що передбачає ранню і точну діагностику причин холестазу, а також залучення малоінвазивних ендобіліарних втручань в подальшому дасть змогу поліпшити результати ліку-

(С) Борисенко В.Б., 2019 
вання цієї категорії хворих.

Мета дослідження: оптимізація програми комплексної діагностики та лікування хворих 3 порушенням дистальної прохідності холедоха непухлинного генезу.

Матеріал і методи. Робота базується на результатах ретроспективного дослідження та лікування 120 пачієнтів віком від 18 до 85 років (се-

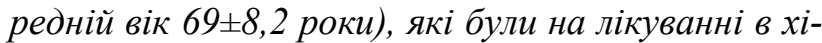
рургічних клініках №2 та №25 м. Харкова в 20122018 роках зі синдромом порушення дистальної прохідності холедоха. Жінок було 76 (63,3\%), чоловіків - 44 (36,7\%).

Програма обстеження містила стандартну клініко-лабораторну діагностику, а також інструментальну із застосуванням ультразвукового дослідження (УЗД), дуоденопапілоскопії (ДПС), ендоскопічної ретроградної холангіографії (ЕРХГ) та, за необхідності, комп'ютерної томографії (КT). Порушенням дистальної прохідності холедоха вважали дилятацію загальної жовчної протоки за даними УЗД більше 6 мм. Цим паизінтам у подальшому виконували ДПС та ЕРХГ.

Лікувальна програма у пацієнтів зі синдромом МЖ на периому етапі мала у своєму складі ендоскопічні транспапілярні втручання. При їх неефективності - черезшкірну черезпечінкову холангіостомію (ЧЧХС) та хірургічну корекцію основного захворювання на другому етапі лікування.

Результати дослідження оброблені статистично з використанням пакета програм Microsoft Excel, з очінкою достовірності показників за $t$ критерієм Стьюдента. Різницю вважали достовірною при $p<0,05$.

Результати дослідження та їх обговорення. Порушення дистальної прохідності холедоха з використанням УЗД встановлено у всіх 120 (100\%) хворих (рис. 1). Дилятація загальної жовчної протоки коливалася від 0,7 до 2,5 см в діаметрі. ЕРХГ виконана 118 (98,3 \%) хворим та була успішною після канюляціі ВСДК у 80 (67,8 \%) випадках та в $38(32,2 \%)$ - після діагностичної або лікувальної ендоскопічної папілосфінктеротомії. У 16 (13,3 \%) пацієнтів, окрім різкого спазму ВСДК і затримки евакуації контрасту, жодної органічної патології не виявлено. За результатами ДПС та ЕРХГ, найбільш частою причиною непрохідності жовчних проток стеноз ВСДК у 52 (43,3 \%) хворих. Ізольовано ця патологія виявлена в 40 (16,7 \%) випадках, а в поєднанні з холедохолітіазом - у 32 (26,7 \%) хворих.

Другою за частотою причиною порушення прохідності холедоха був холедохолітіаз (рис. 2), який виявлено у 48 (40\%) хворих. Дефекти наповнення загальної жовчної протоки при ЕРХГ мали від 0,4 до 2,4 см. У 8 (6,7 \%) хворих причиною холестазу був камінь ампули ВСДК, який у всіх ви-

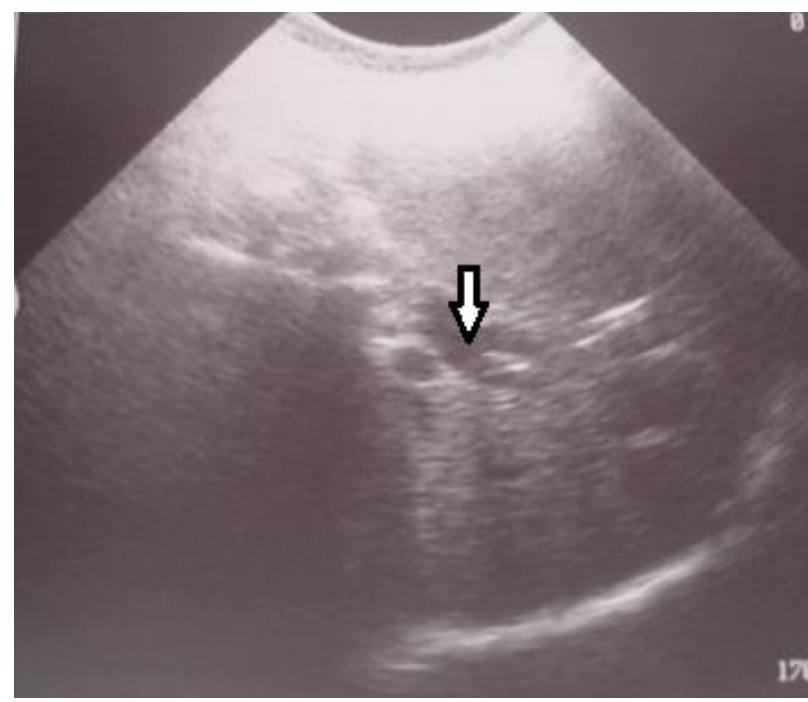

Рис. 1. Сонографічна картина жовчної гіпертензії. Відзначається розширення правої, лівої та загальної печінкової протоки (вказано стрілкою)

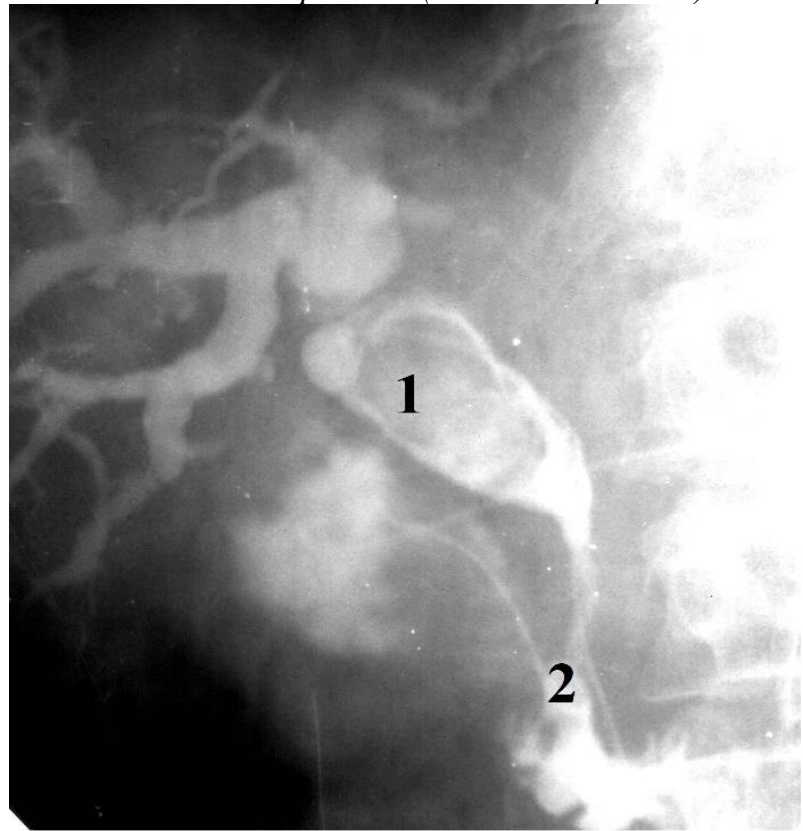

Рис.2. Рентгенограма. ЕРХГ. Великий конкремент (1) проксимальніше стриктури (2) термінального відділу холедоха

падках "відійшов" після ЕПСТ. Поодинокі конкременти дистальної частини загальної жовчної протоки виявлено у 28 (23,3\%), а множинні - у 20 (16,7 \%) хворих. Мікроліти (від 1,0 до 3,0 мм) діагностовані у $6(5,4$ \%) хворих. Ендоскопічно вдалося видалити конкременти від 0,2 до 1,2 см в $40(83,3$ \%) випадках, а в 8 (16,7 \%) - конкременти від 1,7 до 2,4 були визнані такими, що ендоскопічно не видаляються, і цим пацієнтам у подальшому була виконана «відкрита» холедохолітотомія. У всіх випадках холедохолітіаз супроводжувався явищами гострого папіліту.

Назобіліарне дренування, за розробленою нами методикою (Пат. 82642 Україна, МПК А 61 В 17/00. № 201303163) виконано хворим із тяжкою гіпербілірубінемією та явищами холангіту, сричинених мегахоледохолітіазом, синдромом 
Міріззі або стриктурами жовчних протоків у 18 (15\%) випадках. Черезшкірна черезпечінкова етапна холангіостомія виконана 5 (4,2%) хворим переважно при тубулярному стенозі холедоха.

Одноетапне лікування з використанням малоінвазивних ендобіліарних втручань стало остаточним у лікуванні 92 (76,7 \%) пацієнтів із стенозом ВСДК та холедохолітіазом. Двохетапне лікування: ендобіліарне втручання (1-й етап) і відкрите оперативне втручання (холедохолітотомія, накладення біліодигестівного анастомозу та ін.) виконано 12 (10\%) пацієнтам. Лапароскопічна холецистектомія виконана 68 (56,7 \%) хворим 3 калькульозним холециститом. Оперативне лікування не проводилося 16 (13,3 \%) пацієнтам 3 порушенням дистальної прохідності холедоха без ознак органічної патології, зумовленої дисфункцією сфінктера Одді.

Використання запропонованої нами діагностичної програми $з$ пріоритетним залученням УЗД, ДПС та ЕРХГ дало підставу в 117 (97,5 \%) випадках встановити причину холестазу і лише в 3 (2,5 \%) для деталізації діагнозу застосувати КТ. Комплексна консервативна терапія та першочергове використання малоінвазивних транспапілярних методик, та при необхідності етапної ЧЧХС, особливо у хворих $з$ тяжкою та критичною гіпербілірубінемією, дало можливість стабілізувати стан хворих та підготувати їх до подальшого етапного малоінвазивного або традиційного оперативного лікування. Запропонована діагностично-лікувальна програма дала підставу суттєво знизити кількість післяопераційних ускладнень та запобігти летальності.

Висновки. 1. УЗД є найбільш інформативним та доступним інструментальним методом діагностики механічного холестазу, що дає змогу до 100 $\%$ випадків встановити наявність жовчної гіпертензії, рівень перешкоди та часто причину обструкціï. 2. Результати УЗД, ДПС та ЕРХГ дають можливість правильно, інтерпретувати та деталізувати причину порушення дистальної прохідності холедоха до 98 \% випадків. 3. Пріоритетним способом хірургічної корекції органічної патології термінального відділу холедоха є малоінвазивні транспапілярні втручання і лише у випадках їх неефективності можливе проведення ЧЧХС та етапних традиційних «відритих» оперативних втручань.

Перспективи подальших досліджень. Використання розробленої нами діагностично-лікувальної програми дасть можливість у перспективі здійснювати більш детальну діагностику органічної патології дистального відділу холедоха та покращити результати лікування цієї категорії хворих, а також стати у нагоді під час розробки програми диференціальної діагностики органічної та функціональної патології ВСДК.

\section{Список використаної літератури}

1. Борисенко ВБ. Біліарний сепсис: принц̧ипи диференціальної діагностики з механічною жовтяницею та гострим холангітом. Архів клінічної медицини. 2014;2(20):17-9.

2. Даценко БМ, Борисенко ВБ. Критерии диагностики и принципь лечения обтураџионной желтухи и ее осложненных форм - острого холангита и билиарного сепсиса. Клінічна хірургія. 2013;3:5-8.

3. Федоров ВЭ, Власов АП, Федосейкин ИВ. Механическая желтуха неопухолевого генеза. М: Наука; 2014: $233 c$.

4. Майстренко НА. Диагностика и лечение синдрома механической желтухи доброкачественного генеза. Анналь хирургической гепатологии. 2011;3(16):26-34.

5. Пархисенко Ю А. Механическая желтуха: современные взгляды на проблему диагностики и хирургического лечения. Украинский журнал хирургии. 2013;3(22):13-20.

6. Lee TH, Park SH. Optimal use of wire-assisted techniques and precut sphincterotomy. Clin Endosc. 2016;49(5):467-74.

7. Adler DG, Lieb II JG, Cohen J, Pike IM, Park WG, Rizk MK, et al. Quality indicators for ERCP. Gastrointest Endosc. 2015;81(1):54-66.

8. Kang MH, Jeong JW, Han JH. Successful hemostasis by using endoscopic band ligation for uncontrolled postendoscopic sphincterotomy bleeding. Gastrointest Endosc. 2014;79(2):336-7.

9. Chathadi KV, Chandrasekhara V, Acosta RD, Decker GA, Early DS, Eloubeidi MA, et al. The role of ERCP in benign diseases of the biliary tract. Gastrointest Endosc. 2015;81(4):795-803.

10. Cotton PB. ERCP (Ensuring Really Competent Practice): enough words-action please! Gastrointest Endosc. 2015;81(6):1337-42.

11. Nakai Y, Isayama H, Sasahira N, Kogure H, Sasaki T, Yamamoto N, et al. Risk factors for post-ERCP pancreatitis in wire-guided cannulation for therapeutic biliary ERCP. Gastrointest Endosc. 2015:81(1);11926.

\section{References}

1. Borisenko VB. Biliarnij sepsis: principi diferencial'nö̈ diagnostiki z mehanichnoju zhovtjaniceju ta gostrim holangitom. Arhiv klinichnoï medicini. 2014;2(20):17-9. (in Ukrainian). 
2. Dacenko BM. Borisenko VB. Kriterii diagnostiki i principy lechenija obturacionnoj zheltuhi i ee oslozhnennyh form - ostrogo holangita i biliarnogo sepsisa. Klinichna hirurgija. 2013;3:5-8. (in Russian).

3. Fedorov VJe, Vlasov AP, Fedosejkin IV. Mehanicheskaja zheltuha neopuholevogo geneza. M. Nauka; 2014: 233 s. (in Russian).

4. Majstrenko NA. Diagnostika i lechenie sindroma mehanicheskoj zheltuhi dobrokachestvennogo geneza. Annaly hirurgicheskoj gepatologii. 2011; 3(16): 26-34. (in Russian).

5. Parhisenko JuA. Mehanicheskaja zheltuha: sovremennye vzgljady na problemu diagnostiki $i$ hirurgicheskogo lechenija. Ukrainskij zhurnal hirurgii. 2013;3(22):13-20. (in Russian).

6. Lee TH, Park SH: Optimal use of wire-assisted techniques and precut sphincterotomy. Clin Endosc. 2016;49(5):467-74.

7. Adler DG, Lieb II JG, Cohen J, Pike IM, Park WG, Rizk MK, et al. Quality indicators for ERCP. Gastrointest Endosc. 2015;81(1):54-66.

8. Kang MH, Jeong JW, Han JH. Successful hemostasis by using endoscopic band ligation for uncontrolled postendoscopic sphincterotomy bleeding. Gastrointest Endosc. 2014;79(2):336-7.

9. Chathadi KV, Chandrasekhara V, Acosta RD, Decker GA, Early DS, Eloubeidi MA, et al. The role of ERCP in benign diseases of the biliary tract. Gastrointest Endosc. 2015;81(4):795-803.

10. Cotton PB. ERCP (Ensuring Really Competent Practice): enough words-action please! Gastrointest Endosc. 2015;81(6):1337-42.

11. Nakai Y, Isayama H, Sasahira N, Kogure H, Sasaki T, Yamamoto N, et al. Risk factors for post-ERCP pancreatitis in wire-guided cannulation for therapeutic biliary ERCP. Gastrointest Endosc. 2015:81(1);11926.

\section{НЕОПУХОЛЕВОЕ НАРУШЕНИЕ ПРОХОДИМОСТИ ХОЛЕДОХА: ПРИЧИНЫ, ДИАГНОС- ТИКА И ПРИНЦИПЫ ЛЕЧЕНИЯ}

Резюме. Цель исследования. Оптимизация программы комплексной диагностики и лечения больных с нарушением дистальной проходимости холедоха неопухолевого генеза. Материал и методы. Проанализированы результаты обследования и лечения 120 больных с дистальной непроходимостью холедоха неопухолевого генеза. Диагностическая программа включала клинико-лабораторную, ультразвуковую диагностику, папиллоскопию, эндоскопическую ретроградную холангиопанкреатографию и компьютерную томографию. Хирургическое лечение проводилось с приоритетным использованием транспапиллярных эндобилиарных вмешательств, при неэффективности которых выполняли этапную чрескожную чреспеченочную холангиостомию под контролем УЗИ и «открытые» оперативные вмешательства. Результаты. С использованием УЗИ признаки желчной гипертензии были установлены у всех 120 (100 \%) больных. У 94 (78,5 \%) пациентов нарушение дистальной проходимости холедоха сопровождалось механической желтухой. Разработанный нами диагностический алгоритм позволил в 98 \% случаях установить причину холестаза и конечный детализированный диагноз. Одноэтапные транспапилярные вмешательства были эффективными в 92 (76,7 \%) случаях. Чрескожная чреспеченочная этапная холангиостомия выполнена 5 (4,2 \%) больным. В качестве второго этапа лечения, «открытая» холедохолитотомия и билиодигестивные анастомозы произведены 12 (10 \%) больным. 16 (13,3 \%) пациентам, которым была установлена дисфункция сфинктера Одди, оперативное лечение не выполнялось. Выводы. Предложенная нами диагностическая программа с использованием ультразвуковой диагностики, папиллоскопии, эндоскопической ретроградной холангиопанкреатографии позволяет установить детализированный диагноз в $98 \%$ случаев. Приоритетным способом хирургической коррекции органической патологии терминального отдела холедоха и зоны большого дуоденального сосочка являются малоинвазивные транспапиллярные вмешательства и только в случаях их неэффективности возможно проведение этапных чрескожных эндобилиарных декомпрессионных манипуляций и традиционных «отрытых» оперативных вмешательств.

Ключевые слова: дистальная непроходимость холедоха, механическая желтуха, ультразвуковое исследование, эндобилиарные вмешательства.

\section{NON-TUMOROUS CHOLEDOCH PATENCY DISORDERS: CAUSES, DIAGNOSTICS AND PRIN- CIPLES OF THERAPY}

Abstract. Purpose of the study. Optimization of the program of complex diagnostics and therapy of the patients with non-tumorous choledoch distal patency disorders. Material and methods. The results of examination and treatment of 120 patients with non-tumorous choledoch distal patency disorders were analyzed. The diagnostic program included clinico-laboratory, ultrasound diagnostics, papilloscopy, endoscopic retrograde chol- 
angiopancreatography and computer tomography. Surgical treatment was carried out with priority use of transpapillary endobiliary intrusions and when the latter were ineffective staged percutaneous transhepatic cholangiostomy under USD control and "open" operative intrusions were done. Results. Signs of biliary hypertension were found in all $120(100 \%)$ patients under USD. In 94 (78.5\%) patients choledoch distal patency disorders were accompanied by mechanical icterus. The diagnostic algorithm worked out by us allowed the determination of the cholestasis cause and final detailed diagnosis in $98 \%$ of cases. One-stage transpapillary intrusions were effective in $92(76.7 \%)$ cases. Percutaneous transhepatic staged cholangiostomy was done in $5(4.2 \%)$ patients. As for the second stage of the treatment, open choledocholythotomy and biliodigestive anastomoses were done in $12(10 \%)$ patients. $16(13,3 \%)$ patients with stated Oddi's sphincter dysfunction were not operated on. Conclusions. Suggested by us diagnostic program with the use of ultrasound diagnostics papilloscopy, endoscopic retrograde cholangiopancreatography allows the determination of the detailed diagnosis in $98 \%$ of cases. The priority method of surgical correction of the choledoch terminal joint and the zone of large duodenal papilla organic pathology can be mini-invasive transpapillary intrusions and only when they are ineffective the fulfillment of staged percutaneous endobiliary decompression manipulations are possible as well as traditional "open" operative intrusions.

Key words: distal choledoch obstruction, mechanical icterus, ultrasound examination, endobiliary intrusions.

Відомості про автора:

Борисенко Вадим Борисович - доктор медичних наук, професор кафедри ендоскопії та хірургії Харківської медичної академії післядипломної освіти.

Information about the author:

Borysenko Vadym B. - Doctor of Medicine, Professor of Department of Endoskopy and Surgery Kharkiv Medical Academy of Post-Graduate Education.

Надійшла 15.03.2019 p. Рецензент - проф. Шкварковський І.В. (Чернівці) 